Docent dr Ljubiša Vasov,

dipl. inž

Saobraćajni fakultet

Beograd

\section{MODELI FUNKCIJE EFEKTIVNOSTI TEHNIČKIH SISTEMA}

UDC: $62: 519.863$

Rezime:

Efektivnost tehničkog sistema je kompleksni pokazatelj kvaliteta funkcionisanja sistema $i$, zavisno od njegove osnovne namene i funkcije cilja, obuhvata različite karakteristike sistema i procesa održavanja. Odgovarajući modeli ocene funkcije efektivnosti tehničkog sistema obuhvataju relevantne parametre funkcionisanja sistema i ispunjavanja postavljene funkcije cilja. Veliki broj složenih tehničkih sistema zasnovan je na odgovarajućim konstruktivnim i strukturalnim rešenjima, kojima se pri otkazu određene komponente obezbeđuje samo delimično pogoršanje kvaliteta funkcionisanja i smanjenje efektivnosti sistema u celini. Pri ocenjivanju kvaliteta funkcionisanja složenih tehničkih sistema opravdano je uvođenje kvantitativnog uslovnog pokazatelja efektivnosti funkcionisanja, preko kojeg se razmatra uticaj pojave otkaza.

Ključne reči: tehnički sistem, efektivnost, pouzdanost, kvantitativna ocena.

\title{
MODELS OF THE TECHNICAL SYSTEMS EFFECTIVENESS FUNCTION
}

\section{Summary:}

The technical system effectiveness, is a complex indicator of the system functioning quality, and depending on its basic purpose and the objective function, it encompasses different characteristics of the system and the maintaing process. The appropriate models of the effectiveness evaluation of the technical systems include all relevant parameters of the system functioning and they satisfy the objective function. Lot of the complex technical systems are established on the appropriate constructive and structural solutions, which in the case of failure of the specific components, provide only partial deterioration of the function quality evaluation of complex system, it is justified to take into consideration of the quantitative conditional indicator of the effectiveness, which discusses the influence of the mentioned partals failures.

Key words: technical system, effectiveness, reliability, quantitative evaluation.

\section{Uvod}

Jedan od često korišćenih modela, koji je definisan u okviru koncepta efektivnosti vojske (Army System Effectiveness Concept) [1], prema kojem se kvantitativna ocena funkcije efektivnosti tehničkog sistema $E(t)$ vrši na osnovu svoj- stava gotovosti $G(t)$, pouzdanosti $R(t)$ i funkcionalne podobnosti $F P(t)$, može se izraziti kao [2]:

$$
E(t)=f[G(t) \cdot R(t) \cdot F P(t)]
$$

Navedeni model definisan je u obliku proizvoda pokazatelja efektivnosti, a 
ukoliko se pretpostavi da funkcionalna podobnost sistema ne zavisi od vremena, funkcija efektivnosti sistema data je $\mathrm{u}$ obliku [3]:

$$
E(\tau, t)=A(\tau) \cdot R(t) \cdot F P
$$

gde je:

$A(\tau)$ - raspoloživost sistema.

Prema prikazanom modelu funkcije (1), efektivnost sistema $E(\tau, t)$ može se definisati kao verovatnoća ostvarivanja postavljene funkcije cilja, u datom trenutku $(\tau)$ tokom određenog vremena $(t)$ pod specificiranim uslovima okruženja. Kod tehničkih sistema koji se neprekidno koriste [3] najčešće se primenjuje funkcija efektivnosti $E(t)$ u sledećem obliku:

$$
E(t)=G(t) \cdot R(t) \cdot F P
$$

Funkcionalna podobnost (FP) posmatra se deterministički, uz pretpostavku da sistem izvršava predviđenu funkciju cilja u uslovima okruženja za koje je projektovan, tj. da je vrednost funkcionalne podobnosti približno jednaka jedinici $(F P$ $\approx 1)$. Pri tome, kada se radi o popravljivim sistemima, za ocenu efektivnosti interesantna je stacionarna vrednost intervalne pouzdanosti [4], kao verovatnoća da sistem ima stanje ,u radu“ u dovoljno dalekom trenutku i da će raditi bez otkaza tokom zadatog intervala korišćenja, koja se može prikazati relacijom [3]:

$$
E(t)=K_{A} \cdot R(t)
$$

gde je:

$K_{A}$ - koeficijent raspoloživosti.

Međutim, u određenim slučajevima kada se stanje tehničkog sistema ne može potpuno determinisati na stanja radne sposobnosti i otkaza, promena vrednosti funkcionalne pogodnosti ne može se zanemariti i kvalitet funkcionisanja posmatranog sistema određen je funkcijom efektivnosti oblika [3]:

$$
E(t)=G(t) \cdot F P
$$

Treba napomenuti da se kod različitih složenih tehničkih sistema, zavisno od osnovne funkcije cilja i glavnih posledica otkaza, ocena funkcije efektivnosti može definisati i preko pojedinačnih ili kompleksnih pokazatelja, i svesti samo na karakteristike pouzdanosti ili gotovosti.

Bitno je da se uoči činjenica da gotovost i raspoloživost, kao kompleksni pokazatelji efektivnosti, prikazuju svojstva pouzdanosti i pogodnosti održavanja, nezavisno od uslova i dinamike korišćenja tehničkog sistema [2]. Na primer, može se dogoditi da tehnički sistemi koji imaju iste karakteristike pouzdanosti i pogodnosti održavanja, tokom korišćenja pokazuju različitu gotovost i raspoloživost u zavisnosti od koeficijenta intenziteta korišćenja. Zbog toga dati pokazatelji i prikazane funkcije efektivnosti nemaju komparativnu vrednost za različite tehničke sistema iste namene, ukoliko intenziteti korišćenja nisu isti ili nisu svedeni na isti relativni odnos, koji omogućava komparaciju.

Pored toga, važan je probabilistički aspekt prisutan u prikazanom konceptu i stohastička priroda relevantnih parametara, koji efektivnost određuju kao veličinu kategorije verovatnoće. Matematički izrazi za funkcije efektivnosti sistema, dati u obliku proizvoda različitih verovatno- 
ća, mogu se formalno prihvatiti ukoliko parametri koji figurišu u navedenim izrazima predstavljaju međusobno nezavisne slučajne veličine.

\section{Analitički modeli ocene efektivnosti tehničkog sistema}

Pored navedenih oblika funkcija efektivnosti tehničkih sistema, koji su zasnovani na prethodno opisanom konceptu, $\mathrm{u}$ literaturi je prisutan uopšteni sistemski pristup problematici ocene efektivnosti koji, uzimajući u obzir iste pokazatelje, efektivnost u osnovi tretira kao stepen ispunjenja postavljene funkcije cilja. Prema takvom pristupu, efektivnost tehničkog sistema može se definisati kao mera odgovarajućeg stepena realizacije zadataka postavljenih pred sistem, pri određenim uslovima eksploatacije i datom intervalu [5]. Pri tome, pokazatelj efektivnosti predstavlja meru stepena saglasnosti između realnog i traženog rezultata, i može se definisati kao matematičko očekivanje opšte funkcije podudarnosti $(g)$ postignutog rezultata $(Y)$ sa traženim rezultatom $\left(Y_{t t}\right)$ pri izabranoj strategiji $(u)$ eksploatacije sistema [5]:

$$
\begin{aligned}
& E(u)=M\left\{g\left[Y(u), Y_{t r}\right]\right\}, \\
& Y(u)=f[q(u), C(u), T(u)], \quad u \in U
\end{aligned}
$$

gde je:

$q(u)$ - izlazna veličina tehničkog sistema, $C(u)$ - materijalni resursi,

$T(u)$ - vremenski resursi, i

$U$ - skup raspoloživih strategija eksploatacije.

Optimalna strategija $\left(u^{*}\right)$ je strategija iz skupa raspoloživih strategija eksplo- atacije tehničkog sistema $(U)$, kojoj odgovara maksimalna vrednost pokazatelja efektivnosti $E(u)$ pri zadatom nivou eksploatacionog kvaliteta sistema, sa potrebnim troškovima raspoloživih resursa [5]. Time se ukazuje na činjenicu da efektivnost funkcionisanja sistema zavisi od nivoa kvaliteta sistema i procesa eksploatacije, koji određuje primenjena strategija eksploatacije i uslovi okruženja.

Posmatrano sa matematičkog aspekta, efektivnost funkcionisanja tehničkog sistema često se određuje u obliku verovatnoće ostvarivanja projektovane funkcije cilja u datim uslovima okruženja, odnosno verovatnoće izvršavanja predviđenog zadatka. Međutim, veliki broj tehničkih sistema zasnovan je na odgovarajućim konstruktivnim i strukturalnim rešenjima, kojima se pri otkazu određene komponente sistema obezbeđuje samo delimično pogoršanje kvaliteta funkcionisanja i smanjenje efektivnosti sistema u celini. Pri ocenjivanju kvaliteta funkcionisanja složenih tehničkih sistema opravdano je uvođenje kvantitativnog uslovnog pokazatelja efektivnosti funkcionisanja [6], preko kojeg se tretira uticaj pojave otkaza.

Izbor odgovarajućeg uslovnog pokazatelja efektivnosti zavisi od tipa i namene tehničkog sistema, načina ispunjavanja zadataka, osnovnih funkcionalnih zahteva, oblika izlaznih veličina, karaktera uticaja različitih spoljnih uslova $\mathrm{i}$ drugih faktora, koji se razmatraju za svaki konkretan slučaj. Uslovni pokazatelj efektivnosti kvantitativno karakteriše kvalitet funkcionisanja sistema i, kao fizička veličina, može imati različitu dimenziju, što zavisi od samog izbora. $\mathrm{Na}$ 
primer, kao uslovni pokazatelj efektivnosti može se izabrati osnovna izlazna veličina tipa izvršenog rada, razvijene snage, ostvarene brzine, broja izvršenih radnih operacija u jedinici vremena i dr. Posmatrano kroz ukupni proces korišćenja sistema, u određenim slučajevima opravdano je usvojiti, kao uslovne pokazatelje efektivnosti, i prethodno opisane parametre pouzdanosti ili gotovosti koji se mogu tretirati kao izlazne veličine procesa korišćenja. Međutim, za većinu složenih tehničkih sistema pri ocenjivanju efektivnosti funkcionisanja, neophodno je pristupiti formiranju određenog integralnog pokazatelja, koji na odgovarajući način objedinjava dva ili više različitih uslovnih pokazatelja.

Problem formiranja integralnog uslovnog pokazatelja efektivnosti povezan je sa specifičnostima svakog konkretnog tehničkog sistema u datom procesu korišćenja, koji se može rešiti primenom različitih heurističkih metoda. Pri tome, prema pojedinim autorima (Б. Козлов, И. Ушаков, 1975), ocenu efektivnosti funkcionisanja moguće je generalizovati na dva osnovna tipa sistema [6]: sisteme dugotrajnog dejstva i sisteme kratkotrajnog dejstva.

Sistem dugotrajnog dejstva ispunjava određeni zadatak ili vrši predviđenu funkciju od datog trenutka $(\tau)$ tokom intervala vremena korišćenja $\left(t_{k}\right)$, pri čemu efektivnost funkcionisanja sistema zavisi od konkretne realizacije promene stanja $\mathrm{u}$ datom periodu $\left(\tau, \tau+t_{k}\right)$. Svaka realizacija ovakvog procesa promene stanja može biti u potpunosti okarakterisana određenim uslovnim pokazateljem efektivnosti funkcionisanja, koji za datu realiza- ciju $\mathrm{u}$ intervalu $\left(\tau, \tau+t_{k \tau}\right)$ predstavlja funkcija vremena.

Sistem kratkotrajnog dejstva ispunjava određeni zadatak ili vrši predviđenu funkciju od trenutka $(\tau)$ tokom intervala vremena $\left(t_{k \tau}\right)$, koji ima takvu dužinu trajanja da tokom perioda $\left(\tau, \tau+t_{k}\right)$ sistem zadržava početno stanje od trenutka $(\tau)$. Teorijski posmatrano, može se uzeti da sistemi kratkotrajnog dejstva predstavljaju specijalni slučaj sistema dugotrajnog dejstva u kojem je zadati interval takav da $\left(t_{k \tau} \rightarrow 0\right)$. Svako stanje sistema kratkotrajnog dejstva potpuno je okarakterisano uslovnim pokazateljem efektivnosti funkcionisanja, koji za posmatrano stanje ima konstantnu vrednost tokom vremenskog intervala $\left(\tau, \tau+t_{k}\right)$.

\section{Ocena efektivnosti funkcionisanja tehničkog sistema kratkotrajnog dejstva}

Opšti pokazatelj efektivnosti funkcionisanja sistema kratkotrajnog dejstva može se odrediti prema sledećoj relaciji [6]:

$$
E(\tau)=\sum_{S} p_{s}(\tau) \cdot \Phi_{s}
$$

gde je:

$p_{s}$ - verovatnoća $s$-tog stanja sistema u trenutku $(\tau)$,

$\Phi_{s}-$ uslovni pokazatelj efektivnosti u $s$ -tom stanju, i

$S$ - prostor svih mogućih stanja sistema u kojem se vrši sumiranje.

Ukoliko se sistem sastoji iz (n) uzajamno nezavisnih elemenata, koji mogu imati jedno od samo dva moguća stanja „u radu“ i „u otkazu“, verovatnoće stanja 
( $p_{s}$ izražavaju se preko pokazatelja pouzdanosti sastavnih elemenata sistema:

$$
\begin{aligned}
& p_{o}(\tau)=r_{1}(\tau) r_{2}(\tau) \quad \ldots \quad r_{n}(\tau)=\prod_{i=1}^{n} r_{i}(\tau), \\
& p_{i}(\tau)=r_{1}(\tau) r_{2}(\tau) \quad \ldots \quad q_{i}(\tau) \quad \ldots \quad r_{n}(\tau)= \\
& =\frac{q_{i}(\tau)}{r_{i}(\tau)} \prod_{k=1}^{n} r_{k}(\tau), \\
& p_{i j}(\tau)=r_{1}(\tau) r_{2}(\tau) \quad \ldots \quad q_{i}(\tau) \quad \ldots \quad q_{j}(\tau) \\
& \ldots . \\
& r_{n}(\tau)=\frac{q_{i}(\tau) q_{j}(\tau)}{r_{i}(\tau) r_{j}(\tau)} \prod_{k=1}^{n} r_{i}(\tau), \text { itd. }
\end{aligned}
$$

gde je:

$p_{o}(\tau)$ - verovatnoća stanja radne sposobnosti svih elemenata sistema,

$p_{i}(\tau)$ - verovatnoća stanja u kojem je samo $i$-ti elemenat „u otkazu“,

$p_{i j}(\tau)$ - verovatnoća stanja u kojem su $i$-ti i $j$-ti elementi ,u otkazu“,

$r_{i}(\tau)$ - verovatnoća stanja radne sposobnosti $i$-tog elementa,

$q_{i}(\tau)$ - verovatnoća stanja ,u otkazu“ $i$ -tog elementa u trenutku $(\tau)$, itd.

gde važi:

$q_{i}(\tau)=1-r_{i}(\tau)$

Broj stanja sistema $(S)$ zavisi od ukupnog broja sastavnih elemenata sistema (n) i dobija se:

$$
S=\left(\begin{array}{l}
n \\
0
\end{array}\right)+\left(\begin{array}{l}
n \\
1
\end{array}\right)+\ldots+\left(\begin{array}{l}
n \\
n
\end{array}\right)=2^{n}
$$

Proces izračunavanja pokazatelja efektivnosti sistema kratkotrajnog dejstva prema relaciji (5) nije komplikovan.
Međutim, kod sistema sa velikim brojem sastavnih elemenata postaje vrlo obiman. Određena pojednostavljenja $u$ proračunu efektivnosti sistema sa velikim brojem elemenata (n) mogu se ostvariti ukoliko je ispunjen sledeći uslov:

$\max q_{i}(\tau) \ll \frac{1}{n}$

Tada se ocena efektivnosti funkcionisanja sistema u datom trenutku $(\tau)$ može odrediti na osnovu približne relacije:

$$
E(\tau) \approx \Phi_{o}\left[1-\sum_{i=1}^{n} q_{i}(\tau)\left(1-\Phi_{i}^{*}\right)\right]
$$

gde je: $\Phi_{i}^{*}=\frac{\Phi_{i}}{\Phi_{o}}$

Prema gornjim relacijama moguće je dobiti opšti izraz za efektivnost funkcionisanja sistema kratkotrajnog dejstva, ukoliko su poznate vrednosti koeficijenata gotovosti i pouzdanosti izvršavanja predviđenog zadatka u stacionarnom režimu, po pojedinačnim elementima. Ukoliko se pretpostavi da sistem ima (n) podsistema, koji imaju poznate koeficijente gotovosti $\left(K_{G 1}, K_{G 2}, \ldots, K_{G n}\right)$ i nezavisno mogu vršiti projektovanu funkciju cilja sa pojedinačnim verovatnoćama izvršenja zadatka $\left(\varphi_{1}, \varphi_{2}, \ldots, \varphi_{n}\right)$, efektivnost funkcionisanja sistema data je ukupnom verovatnoćom ostvarivanja predviđenog zadatka. Ukoliko se dalje posmatra sistem koji sadrži $(n)$ istih podsistema, može se napisati $K_{G 1}=K_{G 2}=\ldots=$ $K_{G n}=K_{G}$, odnosno $\varphi_{1}=\varphi_{2}=\ldots=\varphi_{n}=$ $\varphi$. Tada se, prema prethodno navedenim 
relacijama, verovatnoće stanja sistema $\left(q_{i}\right)$ i vrednosti uslovnog pokazatelja efektivnosti $\left(\Phi_{i}\right)$ mogu prikazati u sledećem obliku:

$q_{i}=1-K_{G} \quad$ za $i=1,2, \ldots, n$,

$\Phi_{o}=1-\prod_{k=1}^{n}(1-\varphi)=1-(1-\varphi)^{n} \quad \mathrm{i}$

$\Phi_{i}=1-\frac{1}{1-\varphi} \prod_{k=1}^{n}(1-\varphi)=1-(1-\varphi)^{n-1}$

za $i=1,2, \ldots, n$.

Pri tome, prema relaciji (7), efektivnost sistema može se prikazati izrazom:

$$
\begin{aligned}
& E=\left[1-(1-\varphi)^{n}\right]-n\left(1-K_{G}\right) . \\
& \cdot \varphi(1-\varphi)^{n-1} .
\end{aligned}
$$

Može se uočiti da efektivnost funkcionisanja sistema, predstavljena kao verovatnoća ostvarivanja predviđene funkcije cilja (dijagram 1), raste sa povećanjem broja radnih podsistema, koji pojedinačno mogu vršiti predviđeni zadatak. Međutim, karakter rasta efektivnosti prethodno opisanog sistema zavisi od verovatnoća pojedinačnog izvršenja zadatka po podsistemima (elementima) datog sistema, i predstavlja jedan od osnovnih

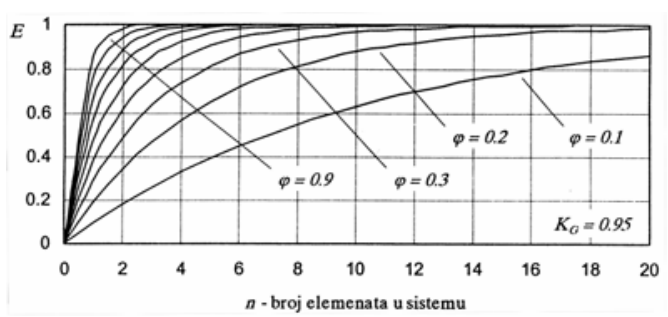

Dijagram 1 -Efektivnost funkcionisanja sistema $u$ zavisnosti od $(n) i(\varphi)$ parametara koji se razmatraju pri dimenzioniranju broja sastavnih elemenata sistema. Pri tome, prema svom značenju, efektivnost funkcionisanja sistema kratkotrajnog dejstva može se posmatrati i kao trenutna efektivnost sistema, koja određuje kvalitet funkcionisanja sistema $\mathrm{u}$ datom momentu $(\tau)$.

Ocena efektivnosti funkcionisanja tehničkog sistema dugotrajnog dejstva

Pokazatelj efektivnosti funkcionisanja sistema dugotrajnog dejstva može se odrediti prema sledećem izrazu [6]:

$$
E\left(\tau, \tau+t_{k \tau}\right)=\int_{G_{\pi}} \Phi_{\pi} d p_{\pi}\left(\tau, \tau+t_{k \tau}\right)
$$

gde je:

$p_{\pi}\left(\tau, \tau+t_{k \tau}\right)$ - verovatnoća $\pi$-te realizacije promene stanja sistema $\mathrm{u}$ intervalu $\left(\tau, \tau+t_{k \tau}\right)$

$\Phi_{\pi}-$ uslovni pokazatelj efektivnosti sistema za $\pi$-tu promenu stanja, i

$G_{\pi}$ - prostor mogućih realizacija procesa promene stanja u intervalu $\left(\tau, \tau+t_{k \tau}\right)$.

Ukoliko se posmatra sistem, koji se sastoji od (n) međusobno nezavisnih i neobnovljivih elemenata sa jednim od dva granična stanja radne sposobnosti ,u radu“ i ,u otkazu“, prethodna relacija (9) može se napisati u obliku:

$$
\begin{aligned}
& E\left(\tau, \tau+t_{k \tau}\right)=\Phi_{o} p_{o}+\sum_{i=1}^{n} p_{i} \int_{\tau}^{\tau+t_{k \tau}} \Phi_{i}\left(t_{i}\right) f_{i}\left(t_{i}\right) d t_{i}+ \\
& +\sum_{1 \leq i<j \leq n} p_{i j} \int_{\tau}^{\tau+t_{k \tau}} f_{i}\left(t_{i}\right) d t_{i} \int_{\tau}^{\tau+t_{k \tau}} \Phi_{i j}\left(t_{i}, t_{j}\right) f_{j}\left(t_{j}\right) d t_{j}+\ldots
\end{aligned}
$$


gde je:

$\Phi_{o}$ - uslovni pokazatelj efektivnosti funkcionisanja sistema kada nijedan elemenat nije otkazao u intervalu $\left(\tau, \tau+t_{k}\right)$;

$\Phi_{i}\left(t_{i}\right)$ - uslovni pokazatelj efektivnosti funkcionisanja sistema kada je otkazao samo $i$-ti element u momentu $\left(t_{i}\right)$ na intervalu $\left(\tau<t_{i} \leq \tau+t_{k \tau}\right)$;

$\Phi_{i j}\left(t_{i}, t_{j}\right)$ - uslovni pokazatelj efektivnosti sistema u slučaju otkaza $i$-tog i $j$-tog elementa u momentima $\left(t_{i}\right)$ i $\left(t_{j}\right)$ na intervalu $\left(\tau<t_{i} \leq \tau+t_{k}\right)$ i $\left(\tau<t_{j} \leq \tau+t_{k}\right)$, itd.;

$f_{i}\left(t_{i}\right)$ - funkcija gustine verovatnoće otkaza $i$-tog elementa u trenutku $\left(t_{i}\right)$;

$p_{o}$ - verovatnoća radne sposobnosti svih elemenata sistema u intervalu $\left(\tau, \tau+t_{k \tau}\right)$;

$$
p_{o}=\prod_{i=1}^{n} r_{i}\left(\tau, \tau+t_{k \tau}\right)
$$

$p_{i}$ - verovatnoća da će $\mathrm{u}$ intervalu $\left(\tau, \tau+t_{k}\right)$ otkazati samo $i$-ti elemenat sistema:

$$
p_{i}=\frac{q_{i}\left(\tau, \tau+t_{k \tau}\right)}{r_{i}\left(\tau, \tau+t_{k \tau}\right)} p_{o}
$$

$p_{i j}$ - verovatnoća da će $\mathrm{u}$ intervalu $\left(\tau, \tau+t_{k \tau}\right)$, otkazati $i$-ti i $j$-ti elementi sistema:

$$
p_{i j}=\frac{q_{i}\left(\tau, \tau+t_{k \tau}\right) q_{j}\left(\tau, \tau+t_{k \tau}\right)}{r_{i}\left(\tau, \tau+t_{k \tau}\right) r_{j}\left(\tau, \tau+t_{k \tau}\right)} p_{o}
$$

Kada je ispunjen sledeći uslov:

$$
\max _{1 \leq i \leq n} q_{i}\left(\tau, \tau+t_{k \tau}\right)=\max _{1 \leq i \leq n} \int_{\tau}^{\tau+t_{k \tau}} f_{i}\left(t_{i}\right) d t_{i} \ll \frac{1}{n}
$$

moguća je približna ocena efektivnosti sistema prema sledećoj relaciji:

$$
\begin{aligned}
& E\left(\tau, \tau+t_{k \tau}\right) \approx \Phi_{o}\left\{1-\sum_{i=1}^{n}\left[q_{i}\left(\tau, \tau+t_{k \tau}\right)-\right.\right. \\
& \left.\left.-\int_{\tau}^{\tau+t_{k \tau}} \Phi_{i}^{*}\left(t_{i}\right) f_{i}\left(t_{i}\right) d t_{i}\right]\right\}
\end{aligned}
$$

gde je:

$\Phi_{i}^{*}\left(t_{i}\right)=\frac{\Phi_{i}\left(t_{i}\right)}{\Phi_{o}}$

Prema prethodnoj relaciji (11), uvođenjem dopunskih pretpostavki, moguće je dobiti opšti izraz za ocenu efektivnosti funkcionisanja sistema dugotrajnog dejstva. Ukoliko se sistem sastoji od (n) podsistema, čiji su pojedinačni rezultati rada usmereni prema ukupnoj veličini funkcije cilja i mogu biti ocenjeni nekom karakterističnom veličinom $\left(\varphi_{1}, \varphi_{2}, \ldots, \varphi_{n}\right)$, pokazatelj efektivnosti sistema određen je obimom ostvarenog izlaznog rezultata. Uvođenjem dodatnih pretpostavki da otkazi podsistema jesu međusobno nezavisni događaji, i da uslovni pokazatelji efektivnosti za pojedinačna stanja sistema mogu biti predstavljeni preko ukupnog izlaznog rezultata rada sistema, koji je proporcionalan vremenu (dijagram 2), može se napisati:

$$
\begin{aligned}
& \Phi_{o}(t)=\varphi_{1} t+\varphi_{1} t+\ldots+\varphi_{n} t=\left(\sum_{j=1}^{n} \varphi_{j}\right) \cdot t \\
& \Phi_{i}\left(t_{i}\right)=\left[\left(\sum_{j=1}^{n} \varphi_{j}\right)-\varphi_{i}\right] \cdot t+\varphi_{i} t_{i}
\end{aligned}
$$




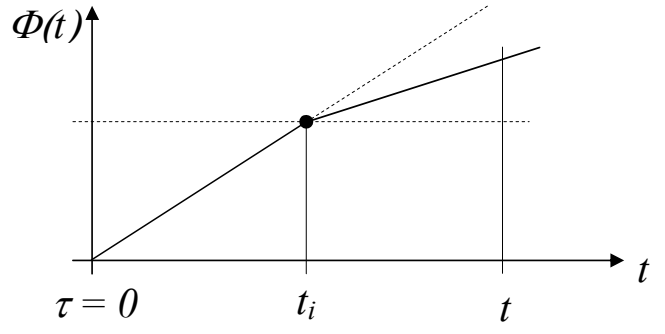

Dijagram 2 - Uslovni pokazatelj efektivnosti sistema dugotrajnog dejstva u funkciji $(t)$

Ukoliko se posmatra sistem koji sadrži (n) istih podsistema, koji imaju eksponencijalne raspodele verovatnoće vremena bezotkaznog rada, može se napisati:

$\varphi_{1}=\varphi_{2}=\ldots=\varphi_{n}=\varphi \Rightarrow \Phi_{o}(t)=n \varphi t$,

$\Phi_{i}\left(t_{i}\right)=(n-1) \varphi t+\varphi t_{i}$,

$\lambda_{1}=\lambda_{2}=\ldots=\lambda_{n}=\lambda$

$\Rightarrow r_{1}(t)=r_{2}(t)=\ldots=r_{n}(t)=r(t)=e^{-\lambda t}$

odnosno

$\Rightarrow f_{1}(t)=f_{2}(t)=\ldots=f_{n}(t)=f(t)=\lambda e^{-\lambda t}$ $q(t)=1-e^{-\lambda t}$

Prema jednačini (11), efektivnost sistema određena je ukupnim izlaznim rezultatom u intervalu $(0, t)$, koji je dat izrazom:

$$
\begin{aligned}
& E(0, t)=n \varphi t \\
& \left\{1-\sum_{i=1}^{n}\left[\left(1-e^{-\lambda t}\right)-\int_{0}^{t} \frac{(n-1) t+t_{i}}{n t} \lambda e^{-\lambda t_{i}} d t_{i}\right]\right\}
\end{aligned}
$$

Izračunavanjem i sređivanjem prethodne jednačine (12) dobija se konačni izraz u sledećem obliku:

$$
E(t)=\frac{n \varphi}{\lambda}\left(1-e^{-\lambda t}\right)
$$

Ukoliko se posmatra dovoljno veliki interval $(t)$, efektivnost funkcionisanja sistema prema izrazu (13) približava se konstantnoj vrednosti (dijagram 3), odnosno:

$$
E=\lim _{t \rightarrow \infty} \frac{n \varphi}{\lambda}\left(1-e^{-\lambda t}\right)=\frac{n \varphi}{\lambda}
$$

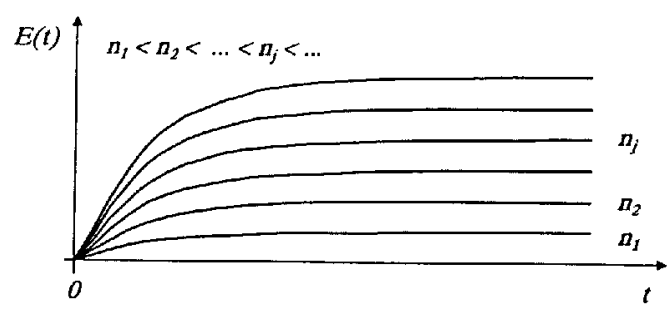

Dijagram 3 - Efektivnost sistema dugotrajnog dejstva u zavisnosti od ( $t$ i $i(n)$

Može se uočiti da efektivnost funkcionisanja prethodno opisanih sistema dugotrajnog dejstva ima svoju asimptotsku vrednost, koja zavisi od broja podsistema (n), njihovih pojedinačnih radnih performansi $(\varphi)$ i karakteristika pouzdanosti ( $\lambda$ ). Pri tome, ovde je efektivnost prikazana preko odgovarajuće fizičke veličine koja opisuje osnovni rezultat rada tehničkog sistema, i može se posmatrati kao kumulativna vrednost ostvarene izlazne veličine sistema. Uzimajući u obzir prethodno navedene činjenice, ovako definisana efektivnost predstavlja ostvarenu efektivnost sistema, koja se odnosi na ukupni kvalitet funkcionisanja sistema $\mathrm{u}$ posmatranom intervalu.

Pored prikazane opšte podele tehničkih sistema u odnosu na karakter trajanja dejstva, postoje sistemi čije je funkcionisanje okarakterisano odgovarajućim oblikom uslovnog pokazatelja efektivnosti, u kojem svaki sastavni elemenat si- 
stema unosi svoj nezavisni udeo u ukupnoj izlaznoj veličini. Navedeni oblik uslovnog pokazatelja efektivnosti karakterističan je za sisteme čija se struktura sastoji od elemenata (podsistema) koji predstavljaju pojedinačne i nezavisne funkcionalne celine. Ocenjivanje efektivnosti takvih sistema, koji mogu biti kratkotrajnog ili dugotrajnog karaktera funkcionisanja, obavlja se preko aditivnih pokazatelja efektivnosti [6].

\section{Ocena efektivnosti funkcionisanja tehničkih sistema sa aditivnim pokazateljima}

Ukoliko je doprinos $i$-tog elementa sistema u ukupnom izlaznom rezultatu funkcionisanja celokupnog sistema odreden aditivnim pokazateljem efektivnosti $\left(\varphi_{i}\right)$, mogu se napisati sledeće relacije:

$$
\begin{aligned}
& \Phi_{o}(t)=\sum_{i=1}^{n} \varphi_{i}(t) \Rightarrow \Phi_{i}(t)=\Phi_{o}(t)-\varphi_{i}(t), \\
& \Phi_{i j}(t)=\Phi_{o}(t)-\left[\varphi_{i}(t)+\varphi_{j}(t)\right], \ldots
\end{aligned}
$$

gde je:

$\Phi_{o}(t)$ - uslovni pokazatelj efektivnosti sistema kada su svi elementi „u radu“,

$\Phi_{i}(t)$ - uslovni pokazatelj efektivnosti kada je $i$-ti elemenat „u otkazu“, i

$\Phi_{i j}(\tau)$ - uslovni pokazatelj efektivnosti kada su $i$-ti i $j$-ti elementi ,u otkazu“.

Ocena efektivnosti funkcionisanja tehničkog sistema kratkotrajnog dejstva ovakvog tipa može se izvršiti na osnovu izraza:

$$
E(\tau)=\sum_{i=1}^{n} \varphi_{i} r_{i}(\tau)
$$

gde je:

$r_{i}(\tau)$ - verovatnoća radne sposobnosti $i$ -tog elementa u trenutku $(\tau)$.

Efektivnost funkcionisanja tehničkog sistema dugotrajnog dejstva, u kojem $i$-ti elemenat doprinosi sa $\varphi_{i}\left(t_{i}\right) \mathrm{u}$ ukupnom izlaznom rezultatu, u slučaju otkaza datog elementa $\mathrm{u}$ trenutku $\left(t_{i}\right) \mathrm{u}$ intervalu $\left(\tau \leq t_{i} \leq \tau+t_{k \tau}\right)$, data je sledećom relacijom:

$$
\begin{aligned}
& E\left(\tau, \tau+t_{k \tau}\right)= \\
& =\sum_{i=1}^{n}\left[r_{i}\left(\tau, \tau+t_{k \tau}\right) \varphi_{o i}+\int_{\tau}^{\tau+t_{k \tau}} \varphi_{i}\left(t_{i}\right) f_{i}\left(t_{i}\right) d t_{i}\right]
\end{aligned}
$$

gde je:

$\varphi_{o i}$ - doprinos $i$-tog elementa u slučaju bezotkaznog rada u intervalu $\left(\tau, \tau+t_{k \tau}\right)$.

Ukoliko sistem sadrži $(n)$ jednakih elemenata (podsistema) sa istim karakteristikama, i ima eksponencijalnu raspodelu vremena bezotkaznog rada, pri čemu su pojedinačni doprinosi u ukupnom izlaznom efektu linearne funkcije vremena, može se napisati:

$$
\begin{aligned}
& \varphi_{1}(t)=\varphi_{2}(t)=\ldots=\varphi_{n}(t)=\varphi \cdot t, \mathrm{i} \\
& \lambda_{1}(t)=\lambda_{2}(t)=\ldots=\lambda_{n}(t)=\lambda
\end{aligned}
$$

Prema relaciji (16), za interval vremena $(0, t)$, može se napisati sledeći izraz:

$$
E(0, t)=\sum_{i=1}^{n}\left(e^{-\lambda t} \varphi \cdot t+\int_{0}^{t} \varphi t \cdot \lambda e^{-\lambda t} d t\right)
$$

Izračunavanjem i sređivanjem prethodnog izraza (17), dobija se konačna relacija: 


$$
E(t)=\frac{n \varphi}{\lambda}\left(1-e^{-\lambda t}\right)
$$

Može se uočiti da je prethodna relacija (18) za efektivnost funkcionisanja sistema identična relaciji (13). Drugim rečima, sistem dugotrajnog dejstva, u opštem slučaju, moguće je svesti na sistem dugotrajnog dejstva sa aditivnim pokazateljima efektivnosti koji su, generalno posmatrano, jednostavniji za razmatranje, ukoliko data struktura i način ostvarivanja izlaznog rezultata funkcionisanja posmatranog sistema to dozvoljavaju. Pri tome, konstatacije koje su izvedene pri analizi efektivnosti funkcionisanja tehničkog sistema dugotrajnog dejstva, mogu se direktno preslikati i na sisteme sa aditivnim pokazateljima efektivnosti.

\section{Zaključak}

Osnovna vrednost navedenih analitičkih modela ocene efektivnosti složenog tehničkog sistema sadržana je u opštem sistemskom pristupu datoj problematici, kojim se, teorijski posmatrano, za pretpostavljene uslove korišćenja sistema funkcionalno integrišu različiti pokazatelji efektivnosti. Potrebno je napomenuti da dati modeli ne obuhvataju eksplicitno sve prethodno opisane pokazatelje efektivnosti sistema, kao što je, na primer, funkcionalna podobnost. Ovakav potencijalni nedostatak može se prevazići uvođenjem uslovnog pokazatelja efektivnosti kompleksnog sadržaja, čime se stvara mogućnost implementacije različitih tehničkih i eksploatacionih relevantnih faktora. Ograničenja koja postoje, pre svega, odnose se na mogućnost uspostavljanja funkcionalne analitičke veze između razmatranih faktora.

Međutim, u prikazanim modelima ocene efektivnosti tehničkog sistema uočavaju se određeni nedostaci koji se mogu tretirati kao posledica prethodno pomenutih ograničenja. Jedan od osnovnih nedostataka vezan je za činjenicu da prikazani modeli ocene efektivnosti ne posmatraju korišćenje tehničkog sistema preko procesa održavanja, i time ne uključuju faktor održavanja sistema i pokazatelj pogodnosti održavanja. Takođe, $\mathrm{u}$ navedenim modelima nisu prisutni faktori koeficijenta intenziteta i dinamike korišćenja sistema, kao osnovni generatori procesa promene stanja sistema. Pored toga, opšta je primedba da data ocena funkcije efektivnosti tehničkog sistema nije svedena na odgovarajući relativni odnos, čime prikazani modeli nemaju praktičnu komparativnu vrednost kod različitih tehničkih sistema.

Literatura:

[1] Blanchard, B. S.; Lowery, E. E.: Maintainability Principles and Practices, McGraw-Hill Book Company, New York, 1969.

[2] Radovanović, V.; Milosavljević, N.: Efektivnost i logistika realnih transportnih sistema, Efektivnost Logistika Informatizacija u Transportu i Saobraćaju - ELITS, Saobraćajni fakultet Univerziteta u Beogradu, Beograd, 14-15. april, 1989, pp 10-24.

[3] Bučevac, I.: Održavanje mašina i opreme, Savez mašinskih i elektrotehničkih inženjera i tehničara Srbije - SMEITS, Beograd, 1996.

[4] Dimitrijević, P.: Istraživanje primene metoda analize efektivnosti u projektovanju sistema sa aspekta funkcije održavanja, doktorska disertacija, Mašinski fakultet Univerziteta u Beogradu, Beograd, 1990.

[5] Никонова, И. А., Шепаль, В. Т.: Техникоэкономическая эффективность авиационных ГТД в експлуатации, Машиностроение, Москва, 1989.

[6] Козлов, Б. А.; Ушаков И. А.: Справочник по расчету надежности апnаратуры радиоэлектроники и автоматики, Советское радио, Москва, 1975. 